\title{
Depression by Association? Mental Well-Being of Women in Urban Slums of Pakistan
}

\author{
Taha Ahmed Ehsan ${ }^{1}$, Fatima Jehangir ${ }^{1} \&$ Rabia Najmi $^{2}$ \\ ${ }^{1}$ Department of Family Medicine, Ziauddin Medical University, Pakistan \\ ${ }^{2}$ Community Health Sciences, Aga Khan University, Pakistan \\ Correspondence: Taha Ahmed Ehsan, Department of Family Medicine, Ziauddin Medical University, Clifton, \\ Karachi, Pakistan. Tel: 92-310-460-4333. E-mail: taha.ehsan@gmail.com
}

Received: February 26, 2021 Accepted: March 15, 2021 Online Published: March 25, 2021

doi:10.5539/gjhs.v13n5p24 URL: https://doi.org/10.5539/gjhs.v13n5p24

\begin{abstract}
Background: The association of mental health with parenthood is complex and varies across many social contexts. Previous studies place mothers with young children at a high-risk for depression. Therefore, the study aimed to understand the association of parity as a risk factor for maternal depression in a cross-sectional survey.
\end{abstract}

Method: A total of 255 women were surveyed at two primary health care centers in Karachi, a Metropolitan city of Pakistan between May 2019 and July 2019 with an anonymously answered Public Health Questionnaire (PHQ) 9. The demographic characteristics and related variables were determined as potential correlates of vulnerability to maternal depression. Significant predictive factors associated with risk factors were analyzed by means of linear correlation and multiple regression analysis.

Results: The PHQ 9 score noted an $89.2 \%$ prevalence of depression in the study sample. Of those, $72.6 \%(0.001$ p-value) were multiparous women (3-5 children). When analyzed within each individual parity category, grand-multiparous women ( 6 or more children) had the highest percentage of depression at $92.6 \%$ followed by multiparous women ( $2-5$ children) at $90.6 \%$.

Conclusion: The result showed the greatest frequency of depression among multiparous women. However, grand multiparous unemployed women were at the highest risk of depression among low-income urban populations.

Keywords: maternal depression, parity, PHQ-9, questionnaire survey, mental wellbeing

\section{Introduction}

Pakistan is the sixth most populous country in the world with a population of over 207 million people according to the census of 2017(Pakistan Bureau Of Statistics, 2017). Studies conducted in Pakistan over the past decade have set the prevalence range between $22 \%$ and a whopping $60 \%$ for anxiety and depression(Ahmed, Enam, Iqbal, Murtaza, \& Bashir, 2016). These high rates coupled with an annual population growth rate of $2.4 \%$ (Pakistan Bureau Of Statistics, 2017) warrants a look at the mental health of the caretakers of the future generation(Niloufer Sultan Ali, Mahmud, Khan, \& Ali, 2013; Gulamani, Shaikh, \& Chagani, 2013; LeMasters et al., 2020; Maselko et al., 2016; Rahman, Lovel, Bunn, Iqbal, \& Harrington, 2004).

The association of mental health with parenthood is complex and varies across the many social contexts. Previous studies place mothers with young children at a high-risk for depression (B. Ali et al., 2002; Naeem, 1992; Rahman et al., 2004). The importance of maternal health and well-being is as important for the growth and development of young children as it is for the mother (Nusrat Husain et al., 2017; Nærde, Tambs, Mathiesen, Dalgard, \& Samuelsen, 2000). This consideration of adverse effects on the children calls for urgent focus to maternal mental health beyond that of the pregnancy and post-partum period that has been studied relatively more in our population (Niloufer S Ali, Azam, Ali, Tabbusum, \& Moin, 2012; Niloufer Sultan Ali et al., 2013; Gul, Sherin, Jabeen, \& Khan, 2017; Gulamani et al., 2013; LeMasters et al., 2020; Rahman et al., 2004; Shah \& Lonergan, 2017).

In our society, caring for the children is considered primarily the mother's responsibility. Hence, the mental well-being of the mother and her children are also linked. The demands of caring for children requires the mother to be emotionally and physically strong (Weissman, Paykel, \& Klerman, 1972). Depression impairs this ability of the mother to cope with the stressors of parenting especially when coupled with other influencing factors such as 
socio-economic status, family unit, education etc. (Heneghan, Silver, Bauman, Westbrook, \& Stein, 1998; Nærde et al., 2000; Rahman et al., 2004). The risk of negative effects of maternal depression on the children (Niloufer Sultan Ali et al., 2013; Nusrat Husain et al., 2017) is significant enough to warrant research to check for stressors that can then be addressed to help them cope (Cree et al., 2018).

The objective of our study is to check for association of bearing and parenting one or more children affects the mental wellbeing of women. This paper attempts to add to the above-mentioned knowledge gap as most of the studies published in Pakistan focus on the post-partum phase only. Evidence is drawn from a cross sectional survey in Pakistan where mothers are considered as the primary caregivers. Two main areas are explored: i) Is there an association of the number of children (parity) with depression in mothers? ii) What are the socio-demographic risk factors for vulnerability to depression in mothers?

\section{Methods}

\subsection{Study Setting}

This cross-sectional survey was conducted in the primary health care center in Clifton and general practice clinic at Qayyumabad, Karachi, Pakistan.

\subsection{Sampling}

All mothers aged 18-48 years with at least one child under the age of 15years (including first time mothers) presenting at the clinic, having no previous history of diagnosed depression and who had given birth to healthy babies were included in the study. Mothers below 18 years and above 48 years, those who could not understand Urdu, those with previous history of diagnosed major depression/anxiety disorders and who used medication for that, and mothers having children with congenital abnormalities or those who had pre-mature babies were excluded, mothers having co-morbids such as thyroid and diabetes were also excluded. A sample size of 255 women was calculated using 5\% margin of error and 90\% Confidence Interval (CI). A total of 350 women were identified as eligible, and of those, 255 consented to be enrolled in the study. Informed consent was obtained at enrollment.

\subsection{Data Collection}

Enrolled women were interviewed using a pre-coded structured questionnaire comprising of questions regarding parity that was noted as the total births including live and still births over 20 weeks of gestational age. In addition, socio-demographic variables including the woman's age, ethnicity, education, working status, family structure was also added to the questionnaire followed by the Patient Health Questionnaire for depression (PHQ9) (Mitchell, Yadegarfar, Gill, \& Stubbs, 2016) to assess the current status of depression or lack of it among participants. The PHQ-9 is a self-administered depression-specific questionnaire developed in the United States of America. The score of the PHQ-9 questionnaire as a measure of severity, ranges from 0-27 as it marks each of the nine criteria from " 0 " (not at all) to " 3 " (nearly every day)(Mitchell et al., 2016). Use of this questionnaire has been validated for primary care setting(Beard, Hsu, Rifkin, Busch, \& Björgvinsson, 2016; Mitchell et al., 2016) and also specifically for Pakistan(Ahmad, Hussain, Akhtar, \& Shah, 2018). The Urdu version of the PHQ-9 has noted a high internal reliability (Cronbach's alpha $=0.844$ ) and high internal consistency (Cronbach's alpha $=0.844$ ) for community-based screening of depressive symptoms in Pakistan (Gallis et al., 2018). A total of 255 women were interviewed between May 2019 and July 2019.

\subsection{Data Analysis}

In the PHQ-9 total score for the nine items ranges from 0 to 27 . The PHQ- 9 depression severity score is 16 ( 3 items scored 1, 2 items scored 2, and 3 items scored 3). Scores of 5, 10, 15, and 20 represent cut points for mild, moderate, moderately severe and severe depression, respectively. Primiparity was coded as having one live or still born, over 20 weeks of pregnancy. Multi parity was coded as having 2 or more live or still born, over 20 weeks of pregnancy. Grand multi parity is defined as having children live or still born over 20 weeks equal to or more than 5 .

SPSS20 was used for data analysis. We ran frequencies and percentages for depression in the study sample. We then ran association of depression with number of children live or still born after 20 weeks of pregnancy. Fischer Exact test was applied to check for significance. Again, a Fischer Exact test was applied, and p-values determined. P-Value less than equal to 0.05 was considered statistically significant.

\subsection{Ethical Consideration}

All women determined eligible were briefed about the study by the researcher and informed consent was obtained before commencing with the interview. For ease of understanding, the questionnaire had been translated into local language Urdu. Confidentiality was maintained by removing personal identifiers and allotting identity (ID) codes 
to the questionnaires. The participants were also given the option of notifying them of positive screening results and/or referral to their medical practitioners. All depression screening results from the study were kept confidential and only shared with the participants and/or their medical practitioner upon participant's consent. They had the right to refuse consent to this information being disclosed. Ethical approval for the study was obtained from the Ziauddin University's ethics review committee (Reference Code: 1950220TAFM).

\section{Results}

Frequency of depression was noted to be $88.6 \%$ (226) of the total 255 women included in the study. Mean age of the study participants was $32.6 \pm 7.1$ yrs. Their ethnic distribution included majority of Punjabis followed by Urdu speaking and Hindko. In addition, there was also Pushtoon, Sindhi and Saraiki representation noted. This ethnic mix is representative of the metropolitan city of Karachi. All our study participants belonged to the low- and lower middle socio-economic status based on their household income.

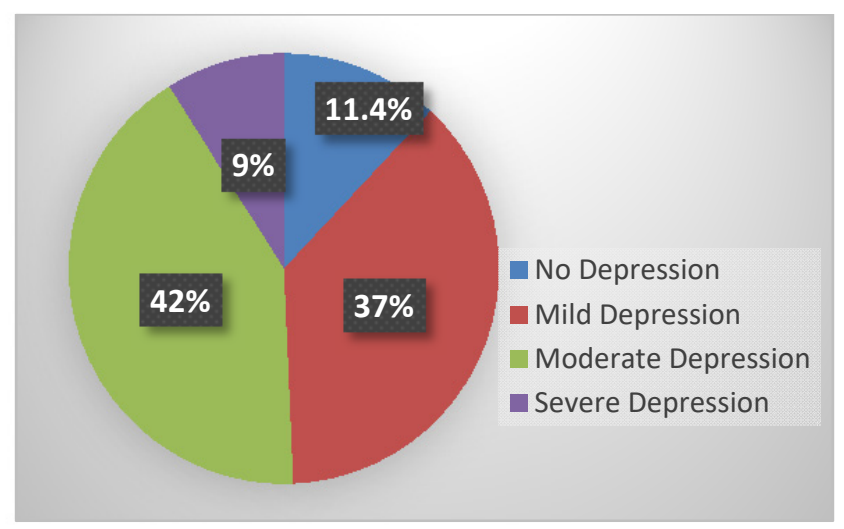

Figure 1. Depression (\%) among participating women

Figure 1 demonstrates that $37.6 \%$ (96) mothers had mild depression, $42 \%$ (107) had moderate depression whereas $9 \%$ (23) had severe depression. (The category of moderately severe and severe was merged into 'severe').

Table 1 revealed that of all those mothers who were depressed, $72.6 \%$ were multiparous ( $2-5$ children) followed by grand-multiparous ( 6 and more children) women at $19.5 \%$ result being statistically significant (p-value 0.001$)$ hence depression showed clear connection with parity in our study.

Table 1. Association of parity and socio-demographic factors with depression

\begin{tabular}{|c|c|c|}
\hline Parameters & Mean \pm SD & Frequency of Depression $n(\%)=226(100)$ \\
\hline Mean age & $32.6 \pm 7.1$ & \\
\hline \multicolumn{3}{|l|}{ Ethnicity } \\
\hline Punjabi & & $69(30.5)$ \\
\hline Urdu speaking & & $61(27.0)$ \\
\hline Hindko & & $44(19.5)$ \\
\hline Pushtoon & & $30(13.3)$ \\
\hline Sindhi & & $17(7.5)$ \\
\hline \multicolumn{3}{|c|}{ Family Structure } \\
\hline Nuclear & & $105(46.5)$ \\
\hline Joint & & $121(53.5)$ \\
\hline \multicolumn{3}{|c|}{ Employment Status } \\
\hline Jobless & & $156(69)$ \\
\hline Full time & & $31(13.7)$ \\
\hline
\end{tabular}




\begin{tabular}{lc}
\hline Part time & $16(7.1)$ \\
Self employed & $23(10.2)$ \\
\hline Education & $62(27.6)$ \\
Illiterate & $29(12.9)$ \\
Primary & $19(8.4)$ \\
Secondary & $47(20.9)$ \\
Metric & $4(1.8)$ \\
Intermediate & $64(28.4)$ \\
College & \\
\hline Parity & $18(8)$ \\
Primiparous & $164(72.6)$ \\
Multiparous & $44(19.5)$ \\
Grand-multiparous & \\
\hline
\end{tabular}

However, when we analyzed the prevalence of depression within each individual parity category using the Exact Fisher Test (Table 2), we noted that $92.6 \%$ of all Grand-multiparous women were depressed and $90.6 \%$ of all multiparous women had depression. This result was statistically significant with a p-value of 0.001 . Since, $53.5 \%$ mothers who were depressed lived in joint families. When education level was analyzed in those that were depressed, $28.4 \%$ (64) went to college while $27.6 \%$ (62) never went to school. Results were statistically significant with a p-value of 0.039 . Employment status of those who were depressed noted that $69 \%$ were jobless.

Table 2. Percentage of depression within each parity category

\begin{tabular}{lll}
\hline Parameters & $\mathbf{\%}$ & $\boldsymbol{p}$-Value \\
\hline Depression in primiparous women & $66.7 \%$ & \\
Depression in multiparous women & $90.6 \%$ & 0.001 \\
Depression in grand multiparous women & $93.6 \%$ & \\
\hline
\end{tabular}

\section{Discussion}

The current study builds on the limited studies on depression among women with young children in Pakistan (B. Ali et al., 2002; Naeem, 1992; Rahman et al., 2004). The results of this study are consistent with other studies of depression among women with young children using standardized symptom and diagnostic assessments (McCue Horwitz, Briggs-Gowan, Storfer-Isser, \& Carter, 2007; Nærde et al., 2000), as well as national studies (B. Ali et al., 2002; N Husain, Creed, \& Tomenson, 2000; Naeem, 1992; Rahman et al., 2004). This high frequency of depression found in mothers in our study suggests that the current mental well-being, is sub-optimal. Upon analyzing the frequency of depression in mothers, the highest number on women with depression was multiparous (Table 1). This being statistically significant and on further analysis, when we studied the prevalence of depression within each category of parity, we found that the women with 5 or more children (Grand multiparous) had 93.6\% depression amongst them making it the highest among all categories (Table 2) with multi parity standing at $90.6 \%$ (Table 2). From the above findings, we establish that while there is greater frequency of depression among multiparous women, the Grand multiparous women are at the greatest risk of depression. The family size in context of maternal mental health in this study appears to be critical as increased number of children may also means increased pressure on family resources and more emotional, physical and mental input required to take care of the family regardless of the economies of scale (Rainwater, 2017).

Previous studies from Iran, Norway and the United states have also reported that larger family size may be responsible for negative effects on the mental health of the family suggesting the possible cause as raising many children with inadequate resources (Grinde \& Tambs, 2016; Molavi, Shargi, Nadermohammadi, Salvat, \& Tavakoli, 2019; Wade \& Kendler, 2000). All our study participants belonged to the low-socio-economic status adding to the already established link identified between mental health and low economic status (Cairney, Boyle, 
Offord, \& Racine, 2003; Israel, Farquhar, Schulz, James, \& Parker, 2002; Mathiesen, Tambs, \& Dalgard, 1999; Moak \& Agrawal, 2010; Wade \& Kendler, 2000). Furthermore, our findings are also in line with the increasing number of studies on depression in low-income earning mothers (Israel et al., 2002; Mathiesen et al., 1999; Wade $\&$ Kendler, 2000). Our study shows a majority of mothers dealing with moderate and severe forms of depression living in a joint family setup. Even if she does seek out support of family members as shown in studies from India and Pakistan (Atif et al., 2017; Atif et al., 2016; Lanes, Kuk, \& Tamim, 2011), there is a high chance it will not be enough to overcome the negative factors of poor financial status, parenting and other associated stressor as noted by a study from rural Pakistan (Maselko et al., 2019). Several studies in the low- and middle-income countries (LMICs) including India, Uganda, Nepal, South Africa, Ethiopia and Pakistan suggest formal management of the depression coupled with informal support would be a more suitable course to take if any noteworthy improvement in mental health outcomes is expected in these mothers of young children (Baron et al., 2016; Malik, Khan, Hussain, \& Hashmi, 2019).

Finally, our findings are in contradiction to earlier research (McCue Horwitz et al., 2007), that states that completing equal to or more than twelve years of schooling was associated with a higher probability of depression. Studies also shows that women having higher education level and belonging to the low socio-economic status may be at increased risk of depression (Beeber et al., 2014). In contrast, our study showed that even though the population that visited the clinics were of low socio-economic background, illiterate women and women possessing college level education were nearly equally depressed. A possible explanation for this may be that a majority of these women were also unemployed which may be another important contributing factor. It appears that education may not shield these women against depression, probably because of the other associated factors of being poor, with multiple children, and unemployed. Further research in this area is recommended to deepen our understanding. Given the resource constraint of a developing country such as Pakistan, we may want to dig deeper into other factors affecting maternal mental health when designing health and well being intervention for the economically vulnerable population. Our study findings suggest that in addition to the current focus on education attainment for health and well being interventions, family planning initiatives also need refocusing and reforming as it empowers these women to determine the number and spacing of children (Miller \& Babiarz, 2016; Prata et al., 2017). Consideration should also be given to other social support initiatives (Atif et al., 2016; Nusrat Husain et al., 2017; Naeem, 1992) such as the employment support programs, child support and access to mental health services. Evidence from other LMICs namely India, Uganda and South Africa suggests that women are open to 'talking therapies' more formally known as psychosocial interventions than taking medicines for treating depression (Baron et al., 2016). Otherwise, the efforts may not be sufficient to protect young families from the detrimental effects of maternal depression and achieve the Sustainable Development Goals of promoting good health and wellbeing (Starbird, Norton, \& Marcus, 2016).

There are several limitations worth noting in this study. Firstly, this study is missing a baseline assessment of depression history if any in the participants prior to entering the study. Secondly, our variables were limited to education, family setup and employment status and parity. Other risk factors (e.g., substance use) associated with maternal depression (Heneghan et al., 1998) were excluded from this analysis because of the amount of missing data. Thirdly, we limited our sample to those who visited the health facilities and volunteered to participate. As a result, the findings may reflect sample bias. We however applied the Simple Random Sampling technique, a proven effective method researcher used to prevent sampling bias and our samples were selected strictly by chance (Smith, 2008).

\section{Conclusion}

Our findings establish a clear association of parity with depression in women with more than one child. It also shows that Grand-multiparous women with six or more children were at highest risk of depression in low-income urban population. The importance of minimizing the stressors of bearing and parenting, larger families need to be considered when planning and resourcing interventions. Further studies into the links of parity with depression in mothers and the stressors of bearing and parenting are needed. Our study contributes to the knowledge base regarding depression in women in the hope for other studies to build on it and highlight the issue regarding depression in the community to inform policies around family planning, social support and chronic stressors that contribute to mental health problems in the community.

\section{Acknowledgements}

We thank consultant family physicians and staff of Qayyumabad General Practice clinic for facilitating the study. 


\section{Ethics Approval}

Ethical approval for this study was sought from the Ethics Review Committee of Ziauddin Medical College, Pakistan. Reference Code: 1950220TAFM.

\section{Patient Consent}

Informed consent was obtained from all the participants of the study.

\section{Availability of Data and Materials}

Study data and material is available on written request to the corresponding author.

\section{Authors Contributions}

TE was involved in conceptualizing, designing, bench work, analysis and writing the manuscript. FJ was involved in writing the manuscript, proof reading and supervising the study. RN's contributions include tool development, literature review, analysis and writing the manuscript.

\section{Competing Interests Statement}

The authors declare that there are no competing or potential conflicts of interest.

\section{References}

Ahmad, S., Hussain, S., Akhtar, F., \& Shah, F. S. (2018). Urdu translation and validation of PHQ-9, a reliable identification, severity and treatment outcome tool for depression. J Pak Med Assoc, 68, 1166-1170.

Ahmed, B., Enam, S. F., Iqbal, Z., Murtaza, G., \& Bashir, S. (2016). Depression and anxiety: a snapshot of the situation in Pakistan. International Journal of Neuroscience and Behavioral Science, 4(2), 32. https://doi.org/10.13189/ijnbs.2016.040202

Ali, B., Rahbar, M., Naeem, S., Tareen, A., Gul, A., \& Samad, L. (2002). Prevalence of and factors associated with anxiety and depression among women in a lower middle class semi-urban community of Karachi, Pakistan. Prevalence.

Ali, N. S., Azam, I. S., Ali, B. S., Tabbusum, G., \& Moin, S. S. (2012). Frequency and associated factors for anxiety and depression in pregnant women: a hospital-based cross-sectional study. The Scientific World Journal, 2012. https://doi.org/10.1100/2012/653098

Ali, N. S., Mahmud, S., Khan, A., \& Ali, B. S. (2013). Impact of postpartum anxiety and depression on child's mental development from two peri-urban communities of Karachi, Pakistan: a quasi-experimental study. BMC psychiatry, 13(1), 274. https://doi.org/10.1186/1471-244X-13-274

Atif, N., Krishna, R. N., Sikander, S., Lazarus, A., Nisar, A., Ahmad, I., . . Rahman, A. (2017). Mother-to-mother therapy in India and Pakistan: adaptation and feasibility evaluation of the peer-delivered Thinking Healthy Programme. BMC psychiatry, 17(1), 79. https://doi.org/10.1186/s12888-017-1244-z

Atif, N., Lovell, K., Husain, N., Sikander, S., Patel, V., \& Rahman, A. (2016). Barefoot therapists: barriers and facilitators to delivering maternal mental health care through peer volunteers in Pakistan: a qualitative study. International journal of mental health systems, 10(1), 24. https://doi.org/10.1186/s13033-016-0055-9

Baron, E. C., Hanlon, C., Mall, S., Honikman, S., Breuer, E., Kathree, T., . . Medhin, G. (2016). Maternal mental health in primary care in five low-and middle-income countries: a situational analysis. BMC health services research, 16(1), 53. https://doi.org/10.1186/s12913-016-1291-z

Beard, C., Hsu, K., Rifkin, L., Busch, A., \& Björgvinsson, T. (2016). Validation of the PHQ-9 in a psychiatric sample. Journal of affective disorders, 193, 267-273. https://doi.org/10.1016/j.jad.2015.12.075

Beeber, L. S., Schwartz, T. A., Martinez, M. I., Holditch-Davis, D., Bledsoe, S. E., Canuso, R., \& Lewis, V. S. (2014). Depressive symptoms and compromised parenting in low-income mothers of infants and toddlers: Distal and proximal risks. Research in nursing \& health, 37(4), 276-291. https://doi.org/10.1002/nur.21604

Cairney, J., Boyle, M., Offord, D. R., \& Racine, Y. (2003). Stress, social support and depression in single and married mothers. Social psychiatry and psychiatric epidemiology, 38(8), 442-449. https://doi.org/10.1007/s00127-003-0661-0

Cree, R. A., Bitsko, R. H., Robinson, L. R., Holbrook, J. R., Danielson, M. L., Smith, C., . . Peacock, G. (2018). Health care, family, and community factors associated with mental, behavioral, and developmental disorders and poverty among children aged 2-8 years-United States, 2016. Morbidity and Mortality Weekly Report, 67(50), 1377. https://doi.org/10.15585/mmwr.mm6750a1 
Gallis, J. A., Maselko, J., O'Donnell, K., Song, K., Saqib, K., Turner, E. L., \& Sikander, S. (2018). Criterion-related validity and reliability of the Urdu version of the patient health questionnaire in a sample of community-based pregnant women in Pakistan. PeerJ, 6, e5185. https://doi.org/10.7717/peerj.5185

Grinde, B., \& Tambs, K. (2016). Effect of household size on mental problems in children: results from the Norwegian Mother and Child Cohort study. BMC psychology, 4(1), 31-31. https://doi.org/10.1186/s40359-016-0136-1

Gul, F., Sherin, A., Jabeen, M., \& Khan, S. A. (2017). Association of stress with anxiety and depression during pregnancy. JPMA. The Journal of the Pakistan Medical Association, 67(12), 1803-1808.

Gulamani, S. S., Shaikh, K., \& Chagani, J. (2013). Postpartum depression in Pakistan. Nursing for women's health, 17(2), 147-152. https://doi.org/10.1111/1751-486X.12024

Heneghan, A. M., Silver, E. J., Bauman, L. J., Westbrook, L. E., \& Stein, R. E. (1998). Depressive symptoms in inner-city mothers of young children: who is at risk? Pediatrics, 102(6), 1394-1400. https://doi.org/10.1542/peds.102.6.1394

Husain, N., Chaudhry, N., Furber, C., Fayyaz, H., Kiran, T., Lunat, F., . . Fatima, B. (2017). Group psychological intervention for maternal depression: A nested qualitative study from Karachi, Pakistan. World journal of psychiatry, 7(2), 98. https://doi.org/10.5498/wjp.v7.i2.98

Husain, N., Creed, F., \& Tomenson, B. (2000). Depression and social stress in Pakistan. Psychological medicine, 30(2), 395-402. https://doi.org/10.1017/S0033291700001707

Israel, B. A., Farquhar, S. A., Schulz, A. J., James, S. A., \& Parker, E. A. (2002). The relationship between social support, stress, and health among women on Detroit's East Side. Health Education \& Behavior, 29(3), 342-360. https://doi.org/10.1177/109019810202900306

Lanes, A., Kuk, J. L., \& Tamim, H. (2011). Prevalence and characteristics of postpartum depression symptomatology among Canadian women: a cross-sectional study. BMC public health, 11(1), 302. https://doi.org/10.1186/1471-2458-11-302

LeMasters, K., Andrabi, N., Zalla, L., Hagaman, A., Chung, E. O., Gallis, J. A., . . Maselko, J. (2020). Maternal depression in rural Pakistan: the protective associations with cultural postpartum practices. BMC public health, 20(1), 1-12. https://doi.org/10.1186/s12889-020-8176-0

Malik, M., Khan, M. U., Hussain, A., \& Hashmi, A. (2019). Cognition and Memory Impairment among Patients of Depression in Pakistan-The Role of Conventional and Newer Anti-Depressants. https://doi.org/10.29328/journal.apmh.1001006

Maselko, J., Hagaman, A. K., Bates, L. M., Bhalotra, S., Biroli, P., Gallis, J. A., . . Rahman, A. (2019). Father involvement in the first year of life: Associations with maternal mental health and child development outcomes in rural Pakistan. Social science \& medicine, 237, 112421. https://doi.org/10.1016/j.socscimed.2019.112421

Maselko, J., Sikander, S., Bangash, O., Bhalotra, S., Franz, L., Ganga, N., . . Rahman, A. (2016). Child mental health and maternal depression history in Pakistan. Social psychiatry and psychiatric epidemiology, 51(1), 49-62. https://doi.org/10.1007/s00127-015-1143-x

Mathiesen, K., Tambs, K., \& Dalgard, O. (1999). The influence of social class, strain and social support on symptoms of anxiety and depression in mothers of toddlers. Social psychiatry and psychiatric epidemiology, 34(2), 61-72. https://doi.org/10.1007/s001270050113

McCue Horwitz, S., Briggs-Gowan, M. J., Storfer-Isser, A., \& Carter, A. S. (2007). Prevalence, correlates, and persistence of maternal depression. Journal of women's health, 16(5), 678-691. https://doi.org/10.1089/jwh.2006.0185

Miller, G., \& Babiarz, K. S. (2016). Family planning program effects: Evidence from microdata. Population and Development Review, 7-26. https://doi.org/10.1111/j.1728-4457.2016.00109.x

Mitchell, A. J., Yadegarfar, M., Gill, J., \& Stubbs, B. (2016). Case finding and screening clinical utility of the Patient Health Questionnaire (PHQ-9 and PHQ-2) for depression in primary care: a diagnostic meta-analysis of 40 studies. BJPsych open, 2(2), 127-138. https://doi.org/10.1192/bjpo.bp.115.001685

Moak, Z., \& Agrawal, A. (2010). The association between perceived interpersonal social support and physical and mental health: results from the National Epidemiological Survey on Alcohol and Related Conditions. Journal 
of public health, 32(2), 191-201. https://doi.org/10.1093/pubmed/fdp093

Molavi, P., Shargi, A., Nadermohammadi, M., Salvat, H., \& Tavakoli, P. (2019). The Relationship between Mental Health of Mothers and Anthropometric Indices of Height and Weight in Children of Ardabil Health Care Centers in 1394The Relationship between Mental Health of Mothers and Anthropometric Indices of Height and Weight in Children of Ardabil Health Care Centers in 1394. Journal of Health, 10(3), 336-345. https://doi.org/10.29252/j.health.10.3.336

Naeem, S. (1992). Vulnerability factors for depression in Pakistani women. J Pak Med Assoc, 42, 137-138.

Nærde, A., Tambs, K., Mathiesen, K. S., Dalgard, O. S., \& Samuelsen, S. O. (2000). Symptoms of anxiety and depression among mothers of pre-school children: effect of chronic strain related to children and child care-taking. Journal of affective disorders, 58(3), 181-199. https://doi.org/10.1016/S0165-0327(99)00119-6

Pakistan Bureau of Statistics. (2017). Provisional summary results of 6th population and housing census. Retrieved from http://www.pbs.gov.pk/content/provisional-summary-results-6th-population-and-housing-census-2017-0

Prata, N., Fraser, A., Huchko, M. J., Gipson, J. D., Withers, M., Lewis, S., . . Upadhyay, U. D. (2017). Women's empowerment and family planning: A review of the literature. Journal of biosocial science, 49(6), 713-743. https://doi.org/10.1017/S0021932016000663

Rahman, A., Lovel, H., Bunn, J., Iqbal, Z., \& Harrington, R. (2004). Mothers' mental health and infant growth: a case-control study from Rawalpindi, Pakistan. Child: care, health and development, 30(1), 21-27. https://doi.org/10.1111/j.1365-2214.2004.00382.x

Rainwater, L. (2017). Family design: Marital sexuality, family size, and contraception: Routledge. https://doi.org/10.4324/9780203792216

Shah, S., \& Lonergan, B. (2017). Frequency of postpartum depression and its association with breastfeeding: A cross-sectional survey at immunization clinics in Islamabad, Pakistan. J. Pak. Medi. Assoc., 67(August (8)), 1151-1156.

Smith, P. L. (2008). An introduction to general sampling principles: reducing bias and variation in bulk sampling. Journal of GXP Compliance, 12(4), 60-66.

Starbird, E., Norton, M., \& Marcus, R. (2016). Investing in family planning: key to achieving the sustainable development goals. Global health: science and practice, 4(2), 191-210. https://doi.org/10.9745/GHSP-D-15-00374

Wade, T. D., \& Kendler, K. S. (2000). The relationship between social support and major depression: cross-sectional, longitudinal, and genetic perspectives. The Journal of nervous and mental disease, 188(5), 251-258. https://doi.org/10.1097/00005053-200005000-00001

Weissman, M. M., Paykel, E. S., \& Klerman, G. L. (1972). The depressed woman as a mother. Social psychiatry, 7(2), 98-108. https://doi.org/10.1007/BF00583985

\section{Copyrights}

Copyright for this article is retained by the author(s), with first publication rights granted to the journal.

This is an open-access article distributed under the terms and conditions of the Creative Commons Attribution license (http://creativecommons.org/licenses/by/4.0/). 